\title{
The Pandemic, Statistics for 2020, Journal Targets and Gastric Cancer
}

When I was appointed as the editorial coordinator of the journal, I pointed out our goals to be reached and the most important one was increasing the quality and visibility of the journal. During the last two years, I believe we have reached that target publishing very high-quality manuscripts with the continuous efforts of the editorial team and the reviewers. I would like to thank all authors for sending their work to the Turkish Journal of Surgery.

2020 will be remembered with the COVID-19 pandemic and unfortunate loses all over the world. Currently, the total number of cases in Turkey is 3.240.577 and total number of deaths is 31.230, including 392 healthcare professionals $(1,2)$.

During the pandemic, we published four issues and 66 manuscripts consisting of 43 original article, 11 case series \& case reports and 3 invited reviews. Although we published 66 articles, we received 274 submissions, 114 of which came from 28 different countries. India, United Kingdom, Pakistan, Iran and Georgia were the first five countries.

Out of 274 submissions, 205 were already evaluated and finalized with an acceptance rate of only 21.5 percent (44 accepted and 161 rejected). Sixty-six articles published in 2020 includes 25 accepted papers from 2020.

During 2020, 274 manuscripts were submitted to the journal and evaluated by 74 reviewers. I would like to thank all of them for their efforts. Final decision for the manuscripts reached within an average of 51.23 days including revisions. Total evaluation time was 3.59 days for the assoc editors' first look, 5.79 days for the reviewers, 26.47 days for the assoc editors' decision, 9.26 days for the authors's revision, and 6.12 days for the editor in chief's decision.

Sixteen papers in 2020 underwent statistical evaluation by the statistical reviewer and average review time was 11.62 days. Five were accepted and 3 rejected directly, and 8 were sent to the authors for revision before acceptance.

CiteScore of the journal was 0.56 in 2018 and it rised to 1.0 in 2019 (evaluated in 2020). CiteScore for 2020 will be available in May 2021. In 2017, 76 documents had 127 citations; in 2018, 76 documents had 119 citations and in 2019, 84 documents had 146 citations, therefore the number of citations is also in a rise (3).

In this first issue of 2021, you will find 11 original articles (3 of them are actually case series), 2 case reports and 1 surgical technique. All of them are very good studies; however, I would like to call your attention to 4 articles on gastric cancer (4-7).

Yüksel A et al. compared laparoscopic and open surgery for gastric cancer, and despite being a low volume center for laparoscopic gastric cancer surgery, they concluded that the risks were similar for both techniques (4).

In another case series study by Kayaalp and his team, although the number was too small, it was found that laparoscopic surgery was technically applicable (5).

In another interesting study by Akcakaya et al. on gastric cancer, they showed that there was no impact of E-cadherin expression on tumoral features and survival in gastric cancer; however, -160 C $\rightarrow$ A polymorphism might influence the expression of E-cadherin in gastric cancer (6).

Ozmen MM et al. compared D2 dissection with D2 plus PALND in patients with advanced gastric cancer and concluded that D2-PALND could be performed safely by experienced surgeons and results in better survival rate especially in patients with advanced disease such as stage IIIA and IIIB (7).

I would also like to take the opportunity to inform you that we will proceed with a new application to Web of Science for inclusion in current contents and SCIE. We will also apply to Pubmed Medline for inclusion. We are currently preparing documents for these applications, and I have every confidence that we will be successful in these steps with the increased quality of the journal.

I extend my sincerest gratitude to every person who has made valuable contributions to the journal. I eagerly look forward to witnessing further advances in the near future.

M Mahir OZMEN MD MS FACS FRCS FASMBS

Professor of Surgery

Editorial Coordinator, Turkish Journal of Surgery

Vice-President, Turkish Surgical Society

Department of Surgery, Medical School, Istinye University, Istanbul, Turkey 


\section{REFERENCES}

1. Worldometer. COVID-19 Coronavirus Pandemic (Coranavirus Cases). Available from: https://worldometers.info/coronavirus

2. Türk Tabipleri Birliği (TTB). Kaybettiklerimiz. Available from: https://www.ttb.org.tr/kollar/COVID19/kaybettiklerimiz.php

3. SJR. Scimago Journal \& Country Rank. Available from: https//wWw.scimagojr.com/journalsearch.php? $q=19283 \&$ tip $=$ sid\&clean $=0$

4. Yüksel A, Coşkun M, Turgut HT, Sümer F. Comparison of open and laparoscopic gastrectomy for gastric cancer: a low volume center experience. Turk J Surg 2021; 37(1):33-40.

5. Çiçek E, Zengin A, Güneş Ö, Sümer F, Kayaalp C. Laparoscopic gastrectomy in remnant gastric cancer. Turk J Surg 2021; 37 (1): 59-62.

6. Akçakaya A, Ünver N, Aydoğan Kiriş T, Güzel M, Akçakaya FB, Çakmakoğlu B, et al. Association of CDH1 -160 C $\rightarrow$ A and -347 G $\rightarrow$ GA polymorphisms and expression of E-cadherin and gastric cancer: A case-control study. Turk J Surg 2021; 37 (1): 41-48.

7. Özmen MM, Zülfikaroğlu B, Özmen F, Moran M, Özalp N, Seçkin S. D2 vs D2 plus para-aortic lymph node dissection for advanced gastric cancer Turk J Surg 2021;37(1):49-58 